\title{
Analysis of card management and associated operational risk in banks of Nepal
}

\author{
Gajendra Sharma $^{1 *}$ and Ravi Shrestha ${ }^{2}$ \\ Department of Computer Science \& Engineering, Kathmandu University, Dhulikhel, Kavre, Nepal ${ }^{1}$ \\ Department of Information Technology, Kantipur City College, (Affiliated to Purbanchal University), Nepal ${ }^{2}$
}

Received: 10-March-2020; Revised: 20-April-2020; Accepted: 22-April-2020

(C)2020 Gajendra Sharma and Ravi Shrestha. This is an open access article distributed under the Creative Commons Attribution (CC BY) License, which permits unrestricted use, distribution, and reproduction in any medium, provided the original work is properly cited.

\begin{abstract}
Analysis of card management and associated operational risk in banks of Nepal' gives us insight on how banks are performing their card management and reconciliation process. This allows us to understand their card management and reconciliation process and operational risk associated with it. Understanding these processes grants us insights to provide suggestions and tips to the employees to efficiently carry out their task. Respondents were provided with questionnaires, and some were interviewed personally regarding the subject matter. The secondary data were collected via reports, journals and websites. After the data collection, it was found that most of the banks are using the card management software and most of them are not efficient enough to satisfy the need of users using it and the institutions. Finally, it is recommended that the institutions should implement few concepts immediately to reduce the operational risk and add additional features to the existing system as mentioned in the prototype.
\end{abstract}

\section{Keywords}

Card management, Bank, Reconciliation, Operational risk, ATM, Maker, Checker, Debit card, Credit card.

\section{Introduction}

Financial institutions, an establishment that conducts financial transactions such as withdraw, deposit, loans, investments, etc. on daily basis have flourished well in our country. Institutions such as banks, credit unions, saving and loan associations, investment companies, brokerage firms, insurance companies fall under this category. They have been providing good service to their customers as per requirements. They provide their service through several mediums and methods; such as cheque, cash, share, e-banking, $\mathrm{debit} / \mathrm{credit} / \mathrm{travel} / \mathrm{prepaid}$ cards, etc.

One of the major institutions through which transactions are carried out is Banks. Banks provide several facilities to their customer to use their services and one of the major methods is via Cheque and ATM Cards (Debit/Credit/Travel/Prepaid Cards). These mediums are easy to use and more widely used in our country than any other. Almost every customer is well aware and notified about the usage of these services [1].

*Author for correspondence

93

\subsection{Objectives}

- To identify and analyze the process of card management in banks of Nepal.

- To identify the operational risk and propose an efficient solution for the card management.

This study is structured as follows: Section 2 includes a literature review of the study. Section 3 is followed by research methodology whereas section 4 provides results and discussion of this study is provided in Section 5. The last section involves conclusions and recommendation.

\section{Literature review}

As per the historical background people used to swap goods in markets in the exchange of gifts where a usually shared system of tokens is suitable. Goods were exchanged in the markets, including useful metals, cattle and sacks of cereal grain. Some situations where people have nothing to exchange, time banking system were established. Time banking is a procedure to exchange services which values as currency unit. Time banking was considered at an hour's worth of individual labor and can be paid with the same amount of work for another person who 
worked for him. This was introduced in preliminary stage as time credit in the UK and time dollar in the USA [2].

Earlier time have been observed a huge development due to the fast development of technology worldwide as well as communication, which led to the need of electronic media and their use, until it became a crucial means in society, making a number of the contract process performed via electronic systems as an alternative to traditional contracts done by telegrams and correspondence; owing to accuracy and speed in drawing up contracts, and effortlessly recognized by electronic system. A product of this progress in the field of communications technology was the need of electronic cards [1].

The history of cash cards and cash machines is very short in Nepal. The USA introduced first cash card system. The cards started to appear initially at the beginning of the 20th century. At that time, they were issued in the form of metal plates or paper booklets. General Petroleum Corporation of California and Western Union were the first companies to issue the cards in 1914 commercially, and Smart and Roebuck introduced in 1917. The rapid development tends to come in the 40-Years and 50-Years. The United States were just undergoing active development during this time. The rapid development of credit cards paid attention of most of the banks, having awareness that they can be a good source of revenue. In the initial phase the cards circulated locally, after that banks began issuing cards which can be used throughout the country and overseas. The earliest local credit card was introduced by the Flatbush National Bank in 1947, and the first card operating across the US was issued by Franklin National Bank in New York, in 1951 [3]. A debit facilitates customers to pay for goods and services by debiting their bank accounts. The credit cards provided the service to obtain credit and withdraw cash up to a prearranged limit.

An ATM transaction includes withdrawing cash from an ATM machine. The user presents an ATM card issued by the bank at an ATM terminal, which may or may not be owned by the same bank. The consumer inserts a personal identification number (PIN) to check identity, the checking account is verified for adequate funds, and if everything is acceptable, cash is issued by the machine. All of these activities are routed across ATM networks. In debit card transaction consumer provides a debit card to a merchant, and the consumer either enters a PIN or signs a receipt to confirm the consumer's identity $[4,5]$. The merchant sends information about the transaction across one or more debit card networks, and if everything is acceptable, the consumer receives the good or service and the checking account is debited. The merchant is reimbursed by a credit to its bank account [6].

As an instance, a user wants to withdraw 50 rupees from the nearest ATM machine immediately he first inserts his card in the machine and he verifies his identity with the PIN number or security code. With the suitable arrangement a link is introduced between the user's account and the bank's financial network. The user gets the approval or denial according to the availability of funds [2].

A number of studies show that the use of debit/credit cards has increased worldwide in recent days. This increasing trend can be attributed to the development in the information technology. The use of debit cards in the USA is rising. The use of debit cards also exceeded the use of credit cards and it contributed the expectations of future financial positions on the use of debit/credit cards [7]. For example, people in the UK use the card "Maestro" and "Solo", Interact is popular among Canadian people, UnionPay in China, Repay in India, VISA, NPN, SCT in Nepal. In the meantime, there are three ways that debit card transactions operate, namely: online debit, offline debit, and electronic purse card system [8].

Among those financial institutions, Banks are rapidly expanding and growing in their size. Banks are now present in every part of the country. They are providing a great deal of service to the customers. The majority of the people in the selected are a preferred ATM service to branch banking, which shows that there is a need of expanding the establishment of ATM vendor machine to include several more areas [9]. With the growing number of customers, the growth of the ATM cards needed in also inevitable as ATM Cards are the primary means through which the customer does the transaction. Being said the primary medium, it is not the only means for the transaction, but due to its easiness, simplicity and quick service customer leans towards the usability of the ATM Card [10].

ATM Cards being the primary means for the transaction, there remains the process of managing those ATM Cards. If there was to be a smaller number of ATM Card users, there would not be any problem in the card management, but we know for 
past few years there has been significant growth in the customers.

The first credit card in Nepal was introduced by Nabil Bank in 1990, and the first ATM was established by the Himalayan Bank in 1995. Although ATM was introduced that time it wasn't in an adequate number. Nowadays, there are more than 9 ATMs per one thousand [11] adults in Nepal, belonging to different banks in various parts of the country. According to the Central Bank of Nepal, there were 5,108,213 debit cards issued as of April 2017 [12, 13], and 6,708,521 debit cards issued as of 2019 [14]. ATM Machine is the terminal which we are taking into consideration in this paper. Finally, the Switch, this is a very powerful device which regulates and performs various activities involved in the transaction of a bank's customer through the terminal. Switch controls every transaction that happens in the terminal, or we can say it controls the terminal itself. Without switch the terminal is just an idle device [15].

ATM reconciliation is about to get familiarity on the difference between ATM balance (as per the book) and as per actual. ATM is basically needed for smooth customers' transactions [16]. Reconciliation compares two sets of records to confirm that figures are accurate. This also verifies that accounts in the general ledger are accurate, consistent and complete [17]. Operational risk may also take place from customer misuse. Many of the manifestations of these risks are applicable to both electronic money and electronic banking [18]. On the other hand, applying an explicit regulatory capital charge against operational risk is new. Basel II needs banks to hold capital against the risk that could arise from the failure of operational systems.

The failure of managing operational risk may result in misstatement of an institution's risk or return profile and expose the institution to great loss. Gross income, used in the Basic Indicator Approach is merely an alternative for operational risk exposure and can underestimate the need for capital [19].

New retail payment mechanisms online also subject users and financial institutions to fraud risk exposure. The automated processes reflect a reengineering of the existing check processes, and the existing fraud controls may not be sufficient. The formation of fraudulent electronic transactions could tend to financial losses [20]. ATM does not require any individual performing the transaction to present picture identification such as sign and physical presence. If the bank card is stolen by the criminal and the PIN number is known, a criminal person can easily make an access to the bank account. There have also been several criminal activities by the Manin-the-middle attacks. The fake keypads are used to read customers' PINs and password to make unauthorized access to the bank customers [21, 22]. In unauthorized use of a payment card, the cardholder's accountability is limited to a specified amount. In order to limit their own losses from POS card fraud, the bankcard companies require vendors to match the cardholder's signature on the card with the signature on the payment voucher at the POS [20].

\section{Research methodology}

\subsection{Conceptual framework}

The research discussed in this paper was inspired by the evolving technology in the banking sector (ATM Cards), its usage, its popularity, challenges in managing the ATM Cards, ATM card management methodologies in different banks of Nepal, its complexity in record keeping and operational risk associated with it. The core conceptual framework of this research can be visualized from the following block diagram as below (Figure 1).

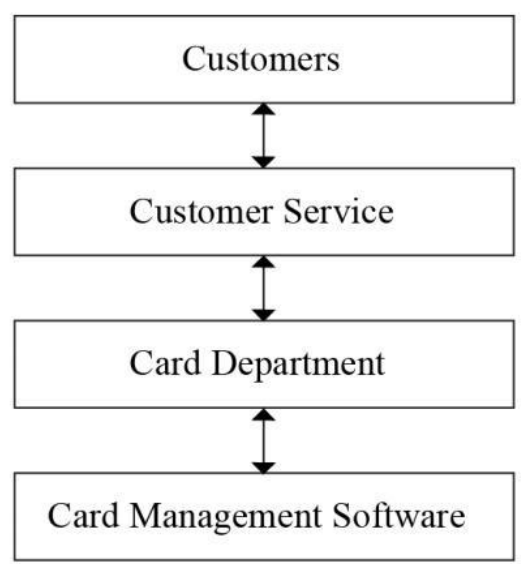

Figure 1 Conceptual framework

Both primary data and secondary data collection method were used in this study. Primary data were collected through questionnaires and interview was conducted with the employees of the bank working in the concerned department. Secondary data are collected via websites (Nepal Rastra Bank), Journal, Articles, etc. The collected data are then analyzed to know and identify the card management process, methods, procedures and operational risk associated with it. 
After the analysis of the data and retrieved information, a proposed system is designed and developed ('Card Management Software') to effectively manage the card and associated procedures. Also provide methods to reduce and mitigate the associated operational risks.

\subsection{Area of study}

The major area of study for this research is the banks and financial institutions of Nepal who are providing their customers with the services of ATM cards. ATM cards include debit card, credit card, travel card, prepaid card, etc. Banks, who possess their own switch are included in the study as well as the banks taking the card hosting services from either other banks or switch providers are included as well. Most banks with their Head Office located inside the Kathmandu Valley are taken into consideration.

Personnel from the card department and IT department are taken into the considerations for this research because they are the ones who are directly involved in the process. This enabled to collect direct feedbacks and answers. Banks and Financial Institutions are very well flourished nation-wide but due to lack of time and availability of resources I am unable to collect data from institutions beyond the valley.

\subsection{Population and sampling}

In this research, the term population refers to all the individuals who are actively involved in the card management process of Banks. Every bank in Nepal now are using card management software, and among them 16 respondents had been chosen for collecting the sample considering the limitations faced.

\section{Results}

This includes the presentation, interpretation and analysis of the relevant data collected via the questionnaires and interview from the employees working in financial institutions concerned department (Card Department / IT Department) for our research. Data are collected from the institutions whose head/branch office is located within the Kathmandu Valley. The data collected are primary in nature. The purpose of this chapter is to introduce the mechanics of data analysis and result out the interpretation. The data analysis procedure involves organizing, tabulating, drawing inferences and conducting statistical analysis. The primary objective of such analysis is to obtain the answers of the questionnaires presented.

4.1Primary data-questionnaires and their analysis 4.1.1Name of financial institutions

Of the total respondents for the research, most of them were from commercial banks and development banks of Nepal. Few of them were from finance companies and some from other financial institutions. As for our research context, major respondents being from the Commercial Banks provide us with a variety of data because the commercial banks are comparatively well exposed and reached to the customer, the card management process, and have also faced various issues related.

Out of the 16 respondents collected, 62.5 percent of the respondents are from commercial banks, 25 percent of development bank, 6.25 percent from Finance and rest from other sectors. This allowed us to gather data from major institution types for our research (Table 1, 2, 3 and 4).

Table 1 List of financial institutions

\begin{tabular}{lll}
\hline S.No & Banks & Types of institutions \\
\hline 1 & Sahayogi Vikas Bank Ltd & Development Bank \\
2 & Kailash Bikas Bank Ltd & Development Bank \\
3 & Jyoti Bikash Bank Ltd. & Development Bank \\
4 & Sanima Bank & Commercial Bank \\
5 & Nepal Investment Bank Limited & Commercial Bank \\
6 & Nepal Bank Limited & Commercial Bank \\
7 & Muktinath Bikas Bank Ltd. & Development Bank \\
8 & Siddhartha Bank Limited. & Commercial Bank \\
9 & Century Commercial Bank limited & Commercial Bank \\
10 & Rastriya Banijya Bank & Commercial Bank \\
11 & NCC BANK LTD. & Commercial Bank \\
12 & Nabil Bank Limited & Commercial Bank \\
13 & Nepal State Bank of India (Nepal SBI) & Commercial Bank \\
14 & Fiserv (Financial Service Provider - & \\
15 & Brookfield, WI) & Others \\
16 & Best Finance Company Ltd & Finance Company \\
\hline
\end{tabular}


Table 2 Count of financial institutions

\begin{tabular}{lll}
\hline Type of institutions & Count of banks & Percentage \\
\hline Commercial Bank & 10 & 62.5 \\
Development Bank & 4 & 25 \\
Finance Company & 1 & 6.25 \\
Others & 1 & 6.25 \\
Grand Total & $\mathbf{1 6}$ & $\mathbf{1 0 0}$ \\
\hline
\end{tabular}

Table 3 Departments of financial institutions

\begin{tabular}{lll}
\hline Variable & Total frequency & Percentage \\
\hline Information Technology & 8 & 57.1 \\
Card Department & 5 & 35.7 \\
Others & 1 & 7.1 \\
Total & $\mathbf{1 4}$ & $\mathbf{1 0 0 . 0}$ \\
\hline
\end{tabular}

Table 4 Methods to improve the current card management system

\begin{tabular}{|c|c|}
\hline Name of financial institution & $\begin{array}{l}\text { If you are given a chance to add some new } \\
\text { techniques, or methods to improve the existing } \\
\text { system of Card Management and make your } \\
\text { work efficient and easy, what would it be? }\end{array}$ \\
\hline Sahayogi Vikas Bank LTD & No \\
\hline Kailash Bikas Bank Ltd & $\begin{array}{l}\text { I would like to add some new techniques regarding } \\
\text { reconciliation }\end{array}$ \\
\hline Jyoti Bikash Bank Ltd. & Upgrading manual form entry to online \\
\hline Sanima Bank & No \\
\hline NIBL & No \\
\hline Nepal Bank Limited & No \\
\hline Muktinath Bikas Bank Ltd. & $\begin{array}{l}\text { Reconciliation module plus card tracking system (delivery of } \\
\text { cards) as well as integration with CBS for various card related } \\
\text { reports }\end{array}$ \\
\hline Siddhartha Bank & Maker-Checker \\
\hline $\begin{array}{l}\text { Century Commercial } \\
\text { Bank limited }\end{array}$ & $\begin{array}{l}\text { There should be some easy way for tracking the international } \\
\text { disputes }\end{array}$ \\
\hline Rastriya Banijya Bank & $\begin{array}{l}\text { The process can be more streamlined if cards from particular } \\
\text { branch can be delivered to other branches as well }\end{array}$ \\
\hline NCC BANK LTD. & No \\
\hline Nabil Bank & No \\
\hline SBI & No \\
\hline Fiserv & No \\
\hline Best Finance Company Ltd & $\begin{array}{l}\text { Actually, till now we are fully satisfied with our CCMS so } \\
\text { there's nothing to improve the existing system at all }\end{array}$ \\
\hline Bank of Kathmandu & $\begin{array}{l}\text { Link card with internet banking and activate/deactivate/set pin } \\
\text { by customer itself }\end{array}$ \\
\hline
\end{tabular}

4.2Secondary data analysis: ATM usage and preference in Nepal

Analyzing through the secondary data, in a survey of the customers of the bank for their behavior and preference it was found that 73 percent of the respondents has ATM cards. There were several prespecified options provided for some of the specific attributes as well as respondents were provided with options to specify their own reason. Major reasons that the respondents considered to be important to choose that particular service had been enlisted. Around $55 \%$ of the respondents stated that the
"Quick service" of their bank lured them to do transactions with it.

This shows the likeliness of the customers in the quick service and choosing of the ATM Service against other services. As we know how quick ATM can provide service to the customers compared to other means.

Similarly, with the preference of the ATM over other medium we can also see the growth of this service flourishing in Nepal. A Study report from Nepal Rastra Bank found that there were 2791 numbers of 
ATM Machine present in our country altogether, and the number of the ATM has increased to 3316 in just one-year term. Similarly, customers using debit card have increased from $5,544,253$ to $6,708,521$ and credit card from 104,721 to 123,146 in just one year. This shows how much there is still potential growth to the usage of these ATM Card Service.

\subsubsection{Operational risk}

Operational risk is as a result of many different internal and external events. The external events can be power failures, floods, terrorist attacks and even earthquakes. Apart from the external events, operational risk can arise from internal events such as the internal failures or shortfalls in any of the bank's processes and systems for example its IT systems. Lack of a risk and compliance management, poor human resources management processes and systems, or poor outsourced service providers, for example bank agents and off-site ATMs can also result in operational risks. Interview with the respondents provided insights with the operational risk associated within the institution.

Firstly, regarding the maker-checker concept, some of the institutions have not implemented this concept. Due to lack of this concept any individual working in the department, assigned with the task of card management can do whatever they please because of absence of the superior for verifying the task he/she does. Even if the user does not have the worst intentions, operations done by him/her might be questioned because it was just performed by one individual and that has not been reviewed by any other. The process of review/checking any work before the approval is vital in these scenarios. Mistakenly multiple cards might have been issued for a single customer, the wrong card request might have been performed, or some minor mistakes might be included in the process. One mistake might be overlooked, but imagine, same mistakes happening repeatedly or via different branches. This only results in the loss for the organization instead of earning some revenue with the service.

In the duration between January to 9 April 2015, the number of attacks on debit cards at ATMs reached the top level in the last 20 years [23]. The criminals are using advanced ways of stealing money and data of users. The popular methods that the criminals are using include ATM hacking, ATM skimming and radio frequency identification (RFID) card skimming. ATM skimming is the process in which criminals use hidden electronics to take personal information of ATM users. Malicious keypads, hidden cameras, and counterfeit card readers are the devices for skimming. The criminals can buy used ATMs, online some of which provide information of users as well as their personal data, that can be accessed without providing credentials. When ATM users are not using the machine, the personal banking information can further be stolen by criminals. Even if modern RFID credit cards use encryption and modern security means, criminals are able to use a homemade skimming device that can get the credit card data without physical touch [24].

Some methods that ATM users can protect their bank account information involve examining the keypad and credit card reader to make sure that a malicious device is not kept on the ATM. An individual can also ensure around the machine for cameras that can be used to record PINs. The users should cover the keypad as they enter their password. ATM users should monitor their bank account online every day to check for transactions that were not made before. Users can also protect their amount and bank account information by avoiding ATMs that are located in hidden or in dark areas [25].

It is seen that more of the younger generation customers tend to use these ATM services for their financial transactions as it is easy and faster means for the transactions. The younger mind sometimes tends to be naive compared to the older generation customers. Banks should educate them about the use of ATMs. Furthermore, banks can draw up special incentives to encourage customers to make the maximum transaction through ATMs [26].

Internal Audit and / or External Auditor may not always be able to capture the actual picture as they submit their report based on the sample audit and it is basically post events. One of the critical components in the operational risk management is human assets (people). People do involve in managing all risks like Credit Risks, Market Risks, Reputational Risks, etc. Unless human assets are strengthened with the required skills for managing all types of risks and cultured with good corporate governance, managing operational risks will not be possible. Operational risks can be mitigated and managed by the combine effort of all Staffs and Board of Directors [27]. The bank provides chip cards to the cardholder to minimize the bank's liability for operational risk related to withdrawing amounts of compromised bank cards [28, 29]. 
Video surveillance cameras can also be used to monitor ATM transactions. They are mounted on and around ATMs to record activities. But regular video surveillance cameras do not have the feature to automatically stop a fraud transaction. However, if a security guard is currently viewing the surveillance feed, the person can take action to protect attacks. The cameras will still be able to capture any malicious activity after-hours at a bank when there is no one monitoring surveillance cameras. The cameras are helpful to record malicious transactions and can assist to recognize the criminals [30].

\section{Discussion}

This study was carried out to identify the process of card management that is being performed in banks and financial institutions in Nepal. Card management focuses on the card issuance of ATM card for customers of the bank who already have an account maintained at the institution. Following the card management process, operational risk associated with it was also taken into consideration for this study. Research was conducted among the major leading banks of Nepal. Respondents interviewed and questioned were from those banks and were actively involved in the card management process in the front line.

Banks in Central and South America, Africa and the Middle East are moving toward biometric technology for ATMs. Fingerprinting technology can be consistent in authenticating ATM users. US has not yet implemented this technology for ATMs because of consumer liability for fraudulent charges and cost of adoption [31]. In addition, consumer privacy is a major difficulty to move forward with adopting this technology. Moreover, fingerprints can simply be lifted and replicated. Criminals can lift and preserve fingerprints with tape and dust. They can collect fingerprints and photograph them with highresolution cameras [32]. The iris scanning technology can also be used instead of fingerprints. Iris scanning technology is an alternative for the future of ATM security.

\subsection{Summary of results}

The research problem gave insight that the rise in the number of customers and their financial activities leads to the rise of ATM Card usage. The data indicated that the increase in the usage of ATM card is significant and is rapidly growing (from 5,544,253 to 6,708,521 debit card users from 2018 to 2019). Data indicates that the card management software that are being used is not effective as it should be. It also indicates that they are likely to face operational risk if they are to continue as it is. Hence the data suggest that an improvement should be made in critical areas and also in the card management software that are being currently used.

\subsection{Implications}

The data contributes a clear understanding of how the process of card management is about the financial institutions and how they are feasible to minimize operational risk. These results should be taken into consideration regarding how to make the card management process efficient and goal oriented because as it was seen previously in the history that poor management could lead to several associated operational risk leading to a loss for the institutions. Not only that a proper card management tool is also simultaneously required as it assists an individual significantly, which ultimately leads to the growth and efficiency of the institution.

\subsection{Limitations}

Most of the respondents from the institutions made clear that they were not satisfied with the tools they have been using and also stated that the tool was lacking some major functionalities. Not only the system portion, but also the managerial portion seemed lacking in the respective departments. It was found that proper management of the team and job division was not present which could eventually lead to some sort or risk to the individual along with the institution itself. Finally, this research was limited to 16 respondents.

\subsection{Contributions}

Previous research and reports demonstrated that there are a number of customers, increasing in the financial institutions. As the customer number increase the amount of ATM card issuance request and ATM card usage increases consequently. In order to effectively manage those requests a proper management tools are required at the user's end. This present research introduces ways to effectively manage the process of card management along with the measures to mitigate the associated operational risks. It also provides tips and feedback for additional functionalities to the existing card management software to ease out the process making it efficient along the way.

\section{Conclusion and recommendation}

This research had been conducted to know the process of card management that is performed on the banks and financial institutions and to find out the operational risk associated with it along with 
providing some tips and recommendations to the existing card management process. The data collected during the research provided the insight of the card management process that is being performed in the institutions. Data indicated that most of the institutions had a proper card management process with effective implementation of maker-checker concept. However, it was also found that there are few of them where these processes have not been implemented, which could result to a potential risk. It was also found that the majority of the institutions are using card management tools for managing and maintaining their card and its respective documents. Based on the above conclusions, practitioners should consider knowing the nature of the process at the current scenario before taking any actions in research because the technology is rapidly evolving which could affect the card management process along with it. The basic management process was missing in some cases which could be primary field of study for future research in its preliminary stage. Several feature additions have been implemented into the prototype system as per the recommendation from the respondents which could be made more effective if they are to be integrated with the organizations existing and core systems for the management process. Reconciliation process will require the analysis of journal files from every terminal available. Automation of journal files into the system database is not implemented in the current prototype, but future researchers could explore the opportunities there.

\section{Acknowledgment}

None.

\section{Conflicts of interest}

The authors have no conflicts of interest to declare.

\section{References}

[1] Kamal A Q, Sulieman A. H. I., Mahmoud A. M. A. $\mathrm{S}$. Electronic credit cards usage and their impact on Bankâ $€^{\mathrm{TM}_{S}}$ profitability: the rate of return on owners equity model "an empirical study". IJCRB Journal, UK. 2012.

[2] https://www.theseus.fi/bitstream/handle/10024/68609/ Thesis_doc.pdf?sequence. Accessed 10 January 2020.

[3] Ilnicki D. The automated teller machine as a new service (Poland case study). Moravian Geographical Reports. 2003; 11(1):20-6.

[4] Nair DJ, Nahar S. ATM transaction: a new time based approach research paper. International Journal of Science, Engineering and Technology Research.2015; 4(6):2254-6.
[5] Hooda K. ATM security. International Journal of Scientific and Research Publications. 2016; 6(4):15966.

[6] Hayashi F, Sullivan RJ, Weiner SE. A guide to the ATM and debit card industry-2006 update. Monograph. 2006.

[7] Simiyu JS, Momanyi G, Naibei KI, Odondo AJ. Credit and debit card usage and cash flow management control by customers: evidences from commercial banks customers in Kisumu City, Kenya. African Research Review. 2012; 6(4):157-72.

[8] http://www.imnepal.com/debit-credit-cards-nepal/. Accessed 10 January 2020.

[9] Dhungel A, Banodita A, Upadhyay-Dhungel K. Perception of bank customers about automated teller machine (ATM) service quality. Banking Journal. 2012; 2(2):23-38.

[10] Kani M, Joy MT. Issues and challenges faced by ATM customers of state bank of India in South Tamil Nadu. Indian Journal of Research. 2013; 2(7):158-61.

[11] https://www.statista.com/statistics/673235/automatedteller-machines-nepal/. Accessed 10 January 2020.

[12] Bank NR. Banking and financial statistics. 2009.

[13] https://blog.khalti.com/fintech-trends/brief-history-ofbanking-in-nepal/. Accessed 10 January 2020.

[14] Bank NR. Financial institutions and its reach in Nepal. RB, Kathmandu, 2019.

[15] Rao S, Mane H. ATM availability management system. IOSR Journal of Computer Engineering. 2018; 2(5): 21-32.

[16] http://www.svtuition.org/2017/05/how-to-do-atmreconciliation.htm. Accessed 10 January 2020.

[17] https://www.investopedia.com/. Accessed 10 January 2020.

[18] https://www.bis.org/publ/bcbs35.pdf. Accessed 20 February 2020.

[19] https://www.nibl.com.np/index.php?option=com_cont ent $\&$ view $=$ article $\& i d=17 \quad$ \&Itemid $=25 \&$ limitstart $=1$. Accessed 10 January 2020.

[20] https://ithandbook.ffiec.gov/media/274860/ffiec_itboo klet_retailpaymentsystems.pdf. Accessed 16 February 2020.

[21] Nuthan K, Nagarathna BM, Sumana NRL, Vidya RB. An automated teller machine: literature review. International Journal of Novel Research in Computer Science and Software Engineering. 2015; 2(1):43-5.

[22] Bhatta KP. Customer behavior and preferences: a survey report. Banking Journal. 2011; 1(1):63-74.

[23] Sidel R. Theft of debit-card data from ATMs soars. The Wall Street Journal. 2015.

[24] Fenlon W. How does ATM skimming work. HowStuffWorks. 2010.

[25] https://crimedoctor.com/. Accessed 20 February 2020.

[26] Vennila A, Rathnaraj SN. Impact on customer perception towards ATM services provided by the banks today: a conceptual study. International Journal of Scientific Research and Management. 2018; 6(1): 31-9. 
[27] Moosa IA. Operational risk management. New York: Palgrave Macmillan; 2007.

[28] Okeke MN, Aganoke CU, Onuorah AN. Operational risk management and organizational performance of banks in, edo state. International Journal of Academic Research Economics and Management Sciences. 2018; 7(4):103-20.

[29] https://www.thebalance.com/atms-use-biometrics-tocombat-fraud-315794. Accessed 20 March 2020.

[30] http://www.forensicsciencesimplified.org/prints/. Accessed 12 March 2020

[31] https://www.isaca.org/resources/isacajournal/issues/2016/volume-2/atm-risk. Accessed 10 March 2020.

[32] https://searchsecurity.techtarget.com/feature/thebasics-of-network-intrusion-prevention-systems. Accessed 12 March 2020.

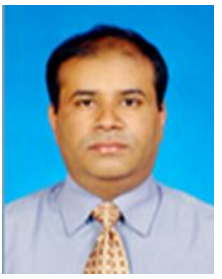

Dr. Gajendra Sharma completed doctoral degree in Information Systems Engineering from Harbin Institute of Technology, China. He received the degree of Masters of Engineering in Electronics and Communication in 1997 from Moscow Technical University of Telecommunication and Informatics, Russia. During the following years, he was employed in different IT companies and corporate organizations in Nepal as a Professional Engineer. He had also worked in a managerial and academic position in different companies and engineering institutions. His research and teaching interest focuses on information systems, e-commerce (including e-business), strategic management of information technology (IT), IT adoption, design and evaluation of IT infrastructure, strategic management of IT as well as e-governance and ethics. Moreover, he has research interest in public administration, conflict management and emergency management. $\mathrm{He}$ published research papers in some of the top-tier information systems and IT journals such as Information Systems Frontiers, Internet Research, Information Technology and People, Telecommunications Policy, International Journal of Web Based Communities and Electronic Commerce Research. He is a reviewer and technical editor of a number of peer review journals relating to information systems and IT. He worked in Liaoning Technical University, China at the department of Information Systems as an Associate Professor from 20112014. He completed postdoctoral research on technology, philosophy (e-government and ethics) from Dalian University of Technology, China is coordinating with Delft University of Technology, Netherlands. In the meantime, he has been working in Kathmandu University, Nepal. Email: gajendra.sharma@ku.edu.np

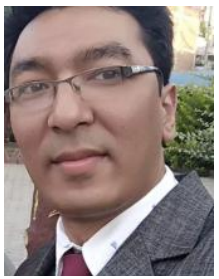

Mr. Ravi Shrestha recently completed Master's degree in Computer Application from Kantipur City College, Affiliated to Purbanchal University, Nepal. His interest of research area is e-Commerce and its applications, IT adoption and information systems. 